\title{
Perceptions of Nurses Before Professional Midwifery in the First Level of Health Care
}

\author{
Dora Gutiérrez Toledo ${ }^{1}$ \\ Technical Secretary of the Inter-Agency Nursing Commission of the State of Chiapas \\ Chiapas State Health Institute \\ Tuxtla Gutiérrez, Chiapas, México
}

\author{
Ivett Reyes Guillén ${ }^{2}$ \\ Faculty of Social Sciences \\ Autonomous University of Chiapas \\ San Cristobal de Las Casas, Chiapas, Mexico
}

\author{
Bárbara Muñoz Alonso Reyes ${ }^{3}$ \\ Therapist TBE and Psychologist Professor \\ Public Health and Developmental Care Research Network, \\ REINVESAD
}

\begin{abstract}
Maternal death is a serious problem of global public health, in many of their cases associated with cultural factors and "uses and customs", this in the different cultures where the problem arises. In Chiapas, Mexico, the approach to traditional midwives represent a concomitant element with aggravated births and need the establishment of professionalization programs for midwives. The objective of this study was to analyse the perceptions of nurses about the impact of professional midwifery on the first level of care A cross-sectional investigation was conducted, showing $n=100$ participants. The results on the perceptions of nurses in the face of professional midwifery at the first level of care are ambiguous, on the one hand, they comprise the main objective of the program and express the motivation for the independent performance of prenatal consulting, consider that a high impact would be achieved in the contribution to the reduction of maternal death. However, their perception of the strategy of boosting professional midwifery in the State of Chiapas is not entirely positive since $28 \%$ regard it as an imposition, others as an irrelevant strategy and $6 \%$ refer that these functions are the responsibility of those who hold the code of license in nursing and obstetrics. Adding difficulties that limit the effective performance of comprehensive care to women in pregnancy, childbirth, and low risk postpartum, highlighting little support from managers, lack of training, lack of inputs, complications of the binomial and medical apathy.
\end{abstract}

Keywords:- Nursing, professional midwifery, perceptions.

\section{INTRODUCTION}

Maternal Death (MM) has been one of the most meaningful public health problems within different societies and throughout the times. In Latin American countries, geographical diversity, socioeconomic and cultural, have been determinants of the lack of equity in efforts aimed at the attention of this problem (ReyesGuillén and Leyva, 2014).

According to data published by WHO on 16 February 2018, maternal mortality is unacceptably high, with approximately 830 women dying worldwide from complications related to pregnancy or childbirth. In 2015, 303,000 deaths of women were estimated during pregnancy and childbirth or related to them. Virtually all these deaths occur in low-income countries and most of them could have been prevented. Since 1990, several sub-Saharan countries have halved their maternal mortality. In other regions, such as Asia and North Africa, progress has been even greater. Between 1990 and 2015, the global MMR (i.e. the number $2.3 \%$ per year. However, from 2000 on, an acceleration of this reduction was observed. In some countries, annual reductions in maternal mortality between 2000 and 2010 exceeded 5.5\% (WHO, 2018).

According to the information published by the Directorate-General for Epidemiology in relation to Maternal Deaths 2018, in Mexico the estimated Maternal Mortality Ratio (RMM) is 30.2 deaths per 100 thousand estimated births, representing a decrease of 11 percentage points compared to the same date last year. The main causes of death are: Obstetric hemorrhage (23.2\%), Hypertensive disease, edema and proteinuria in pregnancy, childbirth and postpartum $(21.7 \%)$ abortion $(8.7 \%)$. The states reporting the highest number of deaths are Chiapas (77), Edo. From Mexico (73), Veracruz (38), Jalisco (36) and Oaxaca (31). (Gob. Mex, 2018).

Chiapas continues to occupy, unfortunately, the first place in maternal mortality in Mexico. Because of this emerging situation in which the State is located and in maternal care, we will talk specifically about professional nurses and traditional midwives.

While the profession in obstetric nursing is a relatively recent field of study-practice in Mexico, this compared to the development of midwives that has a long history beginning with the ancestral practice of traditional midwives across the country, whose services not only constituted a necessary aid for the birth of women from emerging times in the country, if not, a cultural element inseparable from the rite of birth and accompaniment of the mother. of maternal deaths per 100,000 live births) fell by only 
With the formation of the first nursing schools, childbirth is seen as an element of public health and seeks to eradicate the elements potentially dangerous to the mother and newborn. However, this great advance in care still has a reluctance for many communities in Mexico, due to the cultural burden that was established around traditional midwives. That is why the strategy of training professional midwifery, from nurses, is of high impact for the achievement of the articulation between health services and the cultural elements surrounding the search for care by women for monitoring and attention of the process of pregnancy, childbirth and postpartum.

Citing specifically nursing personnel, the InterAgency Nursing Commission of the Ministry of Health launched the "Obstetric Nursing Care Model" (2005). This model aims to harness the potential of nursing staff, especially the graduate in nursing and obstetrics and the perinatal nursing specialist, in order to extend professional care coverage to pregnant women, improve the quality of care and thus contribute to solving the problems of morbidity and maternal mortality in the country. The current model of obstetric care in Mexico has resulted in a high percentage (94\%) institutional births (Gutiérrez et al 2012).

Public hospitals handle many normal deliveries with a human resource shortfall to deal with obstetric emergencies, resulting in a decrease in the quality of care. Faced with this problem, there is the inclusion of professional midwifery and obstetric nurses in the models of care to redistribute normal births to the primary level of health. In this regard, there are successful experiences that indicate the feasibility of carrying these interventions on a larger scale. But in Mexico, it is not yet possible to identify ways to do this exercise in a formal and responsible manner (Macarthur Found, 2013).

By recounting the professionalizing strategies, since the Institute of Health (IESCH, 2019) the Permanent Commission of Nursing has been implemented, in 2016, to address the topic of Strengthening the Practice of obstetric and perinatal nurse, a project that is in charge of the National Center for Gender Equity and Reproductive Health and the Directorate-General for Quality and Health Education , and is instructed for Chiapas, which implements the filling of the Register Card of Nursing Personnel and Technical Midwives for the care of childbirth as well as the description of the activities it carries out.

In 2017, they modify the formats by the National Center for Gender Equity and Health where they inform that the National Registry of Staff providing Midwifery Services is intended to identify health professionals involved in professional midwifery in top-level units and hospitals of the Health Services of federal entities , aiming to improve the processes of registration, concentration and analysis of information.
In 2019 they established a second format "National Register of Nursing Staff Productivity Providing Professional Midwifery Services" that aims to record, unify, concentrate and analyze the activities of perinatal, nursing and obstetrics specialist nurses, technical midwives or other non-medical staff in providing services in the continuum of sexual health care, reproductive, maternal and neonatal in first-level units and hospitals of the health services of federal entities.

Although, these records promote greater control of perinatal health services taking into account cultural factors, their implementation in the State of Chiapas, has caused various dilemmas in the role of nursing personnel who have the training of obstetrics or perinatology because according to the code that it holds, it must fulfill the functions that correspond to it. However, others have been motivated and encouraged by independent consulting at the first level of care by providing low-risk prenatal consultations, without the specialist code.

Professional midwifery offers us opportunities to improve the quality of care and coverage with equity access to health services located in the most marginalized and vulnerable areas. This would be achieved by addressing normal births in world-class health units and thus allowing hospitals to deal only with complicated cases (Fernández, 2018).

Since the past decade, strengthening the role and participation of professional midwifery has been a central component in WHO's special contribution to the Global Initiative for Safe Maternity, Reducing the Risks of Pregnancy. It was launched in 2000, after the 10-year Technical Consultation to review the safe maternity initiative in Colombo, Sri Lanka, in 1997. This unprecedented global consultation worked hard to examine effective interventions for better outcomes in pregnancy and childbirth. The conclusion was that without health service providers with certain midwife skills and competencies, especially life-saving skills, mother, and newborn health goals cannot be achieved (WHO, 2010).

The quality of care provided during childbirth includes the technical and interpersonal competencies of health personnel; but it also depends on the systemic conditions of the service in which they work, and the guarantee of safety, efficiency, equity, acceptability and accessibility of the services.

Despite this, to this day, neither traditional midwives nor professionals have had the proper recognition, nor a clearly defined space of action within the health system. The gap between the cultural and the current continuing health care, but care in health facilities is increasingly totalitarian, creating a new challenge of organizing health services. 
Currently, 96\% of deliveries in Mexico are served in second-tier hospitals, this has led to the saturation of services, which do not always have sufficient staff or material and financial resources to provide quality maternal care. Excessive demand for services has led to situations of mistreatment of women and their newborn, including cases of obstetric violence, in addition the pressure has also led to the routine use of non-evidence-based practices, and to the excessive medicalization of childbirth (Lucille, 2016).

For the above and the interest that research deserves in the area, which allows the contribution to reduce cases of maternal death, this document sets out the results of a study conducted in Chiapas, Mexico, whose main objective was to analyze the perceptions of nurses regarding the impact of professional midwifery on the first level of care.

\section{METHOD}

This research was carried out during 2019, in Chiapas, Mexico. It is of a cross-cutting, qualitative type, that as the main tool for obtaining the information used the structured interview, applying a perception questionnaire to nurses who are working in the first level of care and who carries out activities of professional midwifery.

Population: 2800 nurses of the first level of care distributed in the 10 Health Jurisdictions of the State of Chiapas according to the Federal Platform of the Ministry of Health of the Human Resources Management System in Nursing.

Sample: 100 nurses from the first level of care participating in the Professional Midwifery Registration Format located in different regions of the state of Chiapas (San Cristobal de las Casas, Villaflores, Palenque, Tapachula and Motozintla).

The following sources were used for data collection:

> Human Resources Management System in Nursing period May 2019 Federal platform, for consultation of the number of nursing resources in the first level of care.

$>$ Professional Midwifery Registration Formats period June 2019 Concentrate of the State of Chiapas.

> Interview questionnaires for perceptions applied to nursing staff who are working in health units of the first level of care and who were selected in the representative sample.

\section{DISSCUTION}

The population under study consisted of a representative sample of 100 elements of the nursing staff that are working in health units of the first level of care dependent on the health jurisdictions San Cristóbal de las Casas, Villaflores, Chiapas, Palenque, Tapachula de Córdova and Ordoñez, Tonalá and Motozintla of the Institute of Health of the State of Chiapas, Mexico.
The results found in this research show a predominate of female nurses $(63 \%)$ and an age prevalence of 31 to 39 years $(44 \%)$. Most of the staff interviewed are distributed in Health Centers (94\%) and only 6\% are working in the field, i.e. providing their services in health homes, which shows poor health coverage to the most marginalized and vulnerable population.

The predominant academic training is of graduates in nursing with $56 \%$, general nurses technical $36 \%$ and only $7 \%$ are licensed in nursing and obstetrics. This tells us that there is still a large gap in achieving the skills needed to effectively contribute to reducing maternal morbidity and mortality.

Regarding the perception of the need for training and motivation of the nursing professional in the face of the strategy of the professional midwifery, $69 \%$ consider him a high priority and very high, however; its perception of the strategy of boosting professional midwifery, only $28 \%$ consider it mandatory, 6\% as non-important and another $6 \%$ refers that this strategy should only apply to nurses who have the Employment Code of Bachelor of Nursing and Obstetrics.

This perception checks the theory of Neisser (1979) that tells us that perception is an active-constructive process in which the recipient, before processing the new information and with the data archived in his consciousness, builds an anticipatory informational scheme, which allows him to contrast the stimulus and accept or reject it as indicated or not to what is proposed by the scheme.

In this regard, it is essential to consider that, as a support for vocational nursing training, it is necessary not to neglect the ethical aspects of this discipline, since, in the 21 st century, it would seem that human duty is being carried out by the labor code rather than by ethics itself. Nursing arises from this ethical and moral condition in the face of the need for care, which means that regardless of the labor code that nurses have, it must be able to provide care that guarantees the well-being and safety of people, preserving their health.

Other relevant outcomes are the lack of training on topics related to comprehensive care for women in pregnancy, childbirth and low-risk postpartum; these same issues are those that are part of the proposals expressed by the nurses to strengthen the professional midwifery in the first level of care. Among the topics mentioned as necessary to impart to train nurses are:

$>$ Labor care $(66 \%)$

$>$ Low-risk pregnancy and care $(59 \%)$

$>$ Postpartum care $(18 \%)$

$>$ Obstetric emergency $(14 \%)$ 
The need for training involves reflection for the managers of the various health institutions, because maternal death is an international, national and state problem; and if we relate it to the various strategies and lines of action to accelerate the reduction of maternal death and the Guiding Program of the Permanent Committee on Nursing 2013-2018 in the line of action "Promoting independent and interdependent nursing care at different levels of care for vulnerable groups and with risk factors for noncommunicable diseases, at different stages of people's lives", we can say that there is still a fairly wide gap in the State of Chiapas that requires its attention in the field of training human nursing resources both personally and institutionally.

Among the main difficulties they have faced in order to be able to effectively carry out the activities of professional midwifery, mentioned by $53 \%$ of the staff interviewed, are: the limited support from the management; the lack of training courses related to comprehensive care for women in low-risk pregnancy, childbirth and postpartum; lack of inputs; complications of the binomial and apathy on the part of medical staff.

\section{CONCLUTIONS}

According to the results obtained in the research carried out we can conclude that the perceptions of the nursing staff before the professional midwifery in the first level of care are ambiguous, that is; on the one hand, most understand the main objective of the program and express motivation to carry out prenatal consulting independently, and also consider that prenatal counseling provided by the nursing professional achieved a high impact on the contribution to reducing maternal death.

However, his perception of the strategy of promoting professional midwifery in the State of Chiapas is not entirely positive since, $28 \%$ of them regard it as an imposition, others as an irrelevant strategy and also regard it as responsibility in the roles of specialized personnel, i.e. nursing and obstetrics personnel.

In addition to the above, they add to the difficulties they have faced to effectively perform comprehensive care for women in pregnancy, childbirth and postpartum of low risk:

$>$ Poor support from management

$>$ Lack of training courses related to comprehensive care for women in low-risk pregnancy, childbirth and postpartum

$>$ Lack of inputs

$>$ Complications of the binomial

$>$ Apathy on the part of medical staff

It is essential to consider the training and motivation of nurses as an essential part of strategies to influence the decline in maternal death. In countries such as Mexico, this need is even greater, due to the difficulties that hinder the performance of the health professional in all areas; but that are delicately slowing down the performance of nurses.

\section{REFERENCES}

[1]. Reyes-Guillen Ivett y Leyva CM. Percepciones sobre muerte materna. El punto de vista de parteras tradicionales en zona multicultural y de alta marginación. Revista Médica Electrónica PortalesMédicos.com. 2014 Noviembre; IX(15)

[2]. WHO (2018). Centro de Prensa Mortalidad Materna. [Online].; 2018 [cited 2019 Junio 11. Available from: HYPERLINK "http://www.who.int/es/newsroom/fact-sheets/detail/maternal-mortality" http://www.who.int/es/news-room/factsheets/detail/maternal-mortality

[3]. Gob. Mex. (2018). Epidemiología DGD. www.gob.mx. [Online].; 2018 [cited 2019 Junio 11. Available from: HYPERLINK "http://www.gob.mxx/cms/uploads/attachment/file/42 5158/MM_2018_SE52.pdf" http://www.gob.mxx/cms/uploads/attachment/file/425 158/MM 2018_SE52.pdf

[4]. Secretaría de Salud (2005). MODELO DE ATENCIÓN DE ENFERMERÍA OBSTÉTRICA. http://www.cpe.salud.gob.mx/site3/publicaciones/docs /modelo_atencion_obstetrica.pdf

[5]. GUTIÉRREZ JP, et al., "Encuesta Nacional de Salud y Nutrición 2012. Resultados Nacionales. Cuernavaca", México: Instituto Nacional de Salud Pública (MX), 2012.

[6]. MACARTHUR F (2013). Macfound.org. [Online]. México; 2013 [cited 2019 Junio 11. Available from: HYPERLINK

"https://www.macfound.org/media/office_article_pdfs /13_Parteria_informe_final_FUNDACION_MACAR THUR.pdf"

https://www.macfound.org/media/office_article_pdfs/ 13_Parteria_informe_final_FUNDACION_MACART HUR.pdf

[7]. IESCH (2019). Instituto de Salud del Estado de Chiapas. Experiencia propia laboral. Recuento de experiencias de 2016-2019. Doris Gutiérrez.

[8]. Fernández G O (2018). La contribución de la partería para mejorar la calidad. Boletín CONAMED-OPS. Julio-Agosto 2018; IV(19).

[9]. WHO (2010). Herramientas para el fortalecimiento de la partería profesional:lineamientos para tomadores de decisiones y planificadores para fortalecer la regulación, acreditación y. 2nd ed. CLAP/SMR , editor. Montevideo: CLAP/SMR; 2010.

[10]. Lucille C (2016). Atkin KKBMWRyPS. Fortalecer la partería: Una deuda pendiente con las mujeres de México. Resumen del informe de la línea base de la evaluación. México: Fundación MacArthur, Fundación MacArthur.

[11]. Neisser U (1979). Psicología Cognoscitiva. Tr. Serafín Mercado, México: Trillas 